\title{
Atuações no mercado de capitais combinadas em redes sociais: apontamentos para a atribuição de responsabilidade administrativa e penal por manipulação de mercado
}

\author{
Coordinated negotiations combined on social network: notes for the \\ attribution of administrative and criminal liability for market manipulation
}

Marcelo Costenaro Cavali
Universidade Nove de Julho (Uninove)
Fundação Getúlio Vargas - São Paulo
Pós-doutorado pela Harvard Law School.
Doutor em Direito Penal pela Universidade de São Paulo
Professor da Pós-Graduação Stricto Sensu da Universidade Nove de Julho - São Paulo
e da Fundação Getúlio Vargas - São Paulo
São Paulo - SP - Brasil
mccavali@ @otmail.com
Natalia Naomi Ikeda
Faculdade de Direito da USP
Especialista
Advogada
São Paulo/SP - Brasil
natalia.nikeda@ gmail.com

Resumo: Os autores pretendem apontar elementos a serem considerados, pelas autoridades públicas, para a imputação de responsabilidade, administrativa e penal, em casos de atuações coordenadas de investidores, combinadas em redes sociais, com o objetivo de provocar a elevação dos preços de valores mobiliários. Para tanto, o artigo revisa a escassa bibliografia e a parca jurisprudência existentes. Após examinarem os fundamentos da proibição da manipulação do mercado de capitais, bem como as suas formas de manifestação, os autores mencionam como as modernas formas de comunicação via redes sociais afetaram a produção e a difusão de informações relacionadas a valores mobiliários. Em seguida, analisam as atuações combinadas em redes sociais à luz da infração administrativa de manipulação de preços e do crime de manipulação de mercado. E concluem pela possibilidade de responsabilização administrativa e penal dos líderes desse tipo de atuação.

Palavras-chave: redes sociais; atuações combinadas; manipulação de mercado; responsabilidade administrativa; responsabilidade penal.

\begin{abstract}
The authors intend to stress elements that should be considered by public authorities in the effort to atribute administrative and criminal responsibilities in cases of coordinated actions of investors, combined in social networks, with the objective of causing an increase in the prices of securities. For that purpose, the article reviews the scarce bibliography and the rare
\end{abstract}


CAVALI, Marcelo Costenaro; IKEDA, Natalia Naomi. Atuações no mercado de capitais combinadas em redes sociais: apontamentos para a atribuição de responsabilidade administrativa e penal por

existing jurisprudence. After examining the fundamentals of the prohibition of capital market manipulation, as well as its manifestations, the authors mention how modern forms of communication via social networks have affected the production and dissemination of information related to securities. They then analyze the combined actions on social networks in light of the administrative violation of price manipulation and the criminal offense of market manipulation. In the end they conclude for the possibility of administrative and penal accountability of the leaders of this type of action.

Keywords: social networks; coordinated negotiations; market manipulation; administrative responsability; criminal responsability.

\section{Para citar este artigo}

ABNT NBR 6023:2018

CAVALI, Marcelo Costenaro; IKEDA, Natalia Naomi. Atuações no mercado de capitais combinadas em redes sociais: apontamentos para a atribuição de responsabilidade administrativa e penal por manipulação de mercado. Prisma Jurídico, São Paulo, v. 20, n. 2, p. 375-392, jul./dez. 2021. http://doi.org/10.5585/prismaj.v20n2.21144.

\section{Introdução}

Em janeiro de 2021, o mercado de capitais se viu às voltas com uma nova - ou velha, vestida com roupas novas - forma de atuação conjunta e combinada de investidores. A onda começou nos EUA, quando as ações da companhia norte-americana GameStop se valorizaram $1.600 \%$ em menos de um mês. Crendo na desvalorização do ativo, diante da obsolescência do modelo de negócio da GameStop - uma cadeia com mais de 5 mil lojas de videogame, que vinha sofrendo prejuízos em razão da migração dos consumidores para as lojas virtuais e plataformas de streaming -, alguns fundos de investimento haviam realizado vendas a descoberto (short selling) das ações de emissão da companhia.

Porém, um grupo de investidores passou a incentivar publicamente a compra de ações da GameStop em redes sociais: sem apresentar razões econômicas fundadas para sustentar um prognóstico de valorização do ativo, o movimento era baseado na intenção de minar a estratégia dos fundos de investimento e "ensinar-lhes uma lição". A atuação concertada provocou a valorização abrupta do ativo. Centenas de milhares de microinvestidores seguiram o efeito manada e fizeram com que o preço da ação continuasse a subir. Necessitando comprar ações no mercado para devolver as ações alugadas, cobrindo as obrigações assumidas com o short selling, os fundos de investimento contribuíram ainda mais para a formidável subida da cotação do valor mobiliário (OSIPOVICH, 2021). 
CAVALI, Marcelo Costenaro; IKEDA, Natalia Naomi. Atuações no mercado de capitais combinadas em redes sociais: apontamentos para a atribuição de responsabilidade administrativa e penal por

A mesma tática passou a ser usada em relação a ações de emissão de outras companhias nos EUA, como AMC e Bed Bath \& Beyond (MICHAELS; OSIPOVICH, 2021), e no Brasil, em relação às ações de emissão do IRB (VALENTI, 2021).

No ambiente contemporâneo de inédita polarização e rapidez de informações, logo surgiram versões antagônicas quanto à atuação dos participantes das redes sociais que orquestraram as altas dos preços dos valores mobiliários. Para analistas tradicionais, seriam manipuladores do mercado, criminosos atuando nas redes sociais para promover uma espécie de "arrastão" sobre o patrimônio de grandes fundos e de outros (grandes ou pequenos) investidores desavisados. Já para os defensores da estratégia, eles fariam um papel semelhante ao dos merry men - integrantes do bando de Robin Hood - tirando dinheiro dos ricos fundos especuladores para repassar aos pequenos investidores honestos ${ }^{1}$.

O objeto deste artigo, nesse contexto, consiste em apontar elementos a serem considerados pelas autoridades responsáveis pelo enforcement - isto é, a aplicação das normas repressoras de ilícitos - no mercado de capitais para a atribuição de responsabilidade, administrativa e penal, por esse tipo de conduta. Para tanto, será realizada uma revisão bibliográfica da, ainda parca, bibliografia pertinente ao tema, bem como mencionada a escassa jurisprudência, administrativa e penal, referente à manipulação do mercado.

Como veremos, é que o papel das redes sociais como nova fonte de informações para o mercado alterou sensivelmente a sua dinâmica. A possibilidade de anonimato nas redes sociais, a disseminação acelerada de notícias e a reação imediata dos investidores criaram novas formas de atuação e de manipulação do mercado. Para bem compreender essas mudanças no contexto atual é preciso, antes, examinar os fundamentos da proibição da manipulação do mercado.

\section{A importância fundamental da informação no mercado de capitais}

Para garantir condições mínimas de igualdade de acesso à informação a todos os investidores no mercado de capitais, a legislação exige a divulgação pelas companhias de todos os fatos relevantes que afetem seus negócios (princípio do full and fair disclosure), nos termos do art. $157, \S^{\circ}$, da Lei das S.A. (CAVALI; BALDINI, 2021, p. 47-48).

Os investidores atuam no mercado com motivações e conhecimentos bastante distintos entre si (HARRIS, 2003, p. 176). Apenas certas categorias de investidores efetivamente trabalham com a captação e o processamento especializado de informações, a partir das quais

\footnotetext{
${ }^{1}$ Ironicamente, uma corretora de valores mobiliários chamada Robin Hood passou a ser acusada de manipulação do mercado por ter interrompido as operações de seus clientes com ações da GameStop ao perceber a injustificada alta do seu preço.
} 
CAVALI, Marcelo Costenaro; IKEDA, Natalia Naomi. Atuações no mercado de capitais combinadas em redes sociais: apontamentos para a atribuição de responsabilidade administrativa e penal por manipulação de mercado

comparam o preço dos ativos com seu valor intrínseco. E, ainda assim, a economia comportamental identifica diversos desvios cognitivos em agentes que, supostamente, agiriam de modo racional (THALER, 2015).

Não obstante a constatação empírica de eventuais comportamentos irracionais, a formulação da política pública no âmbito do mercado de capitais deve tomar essa racionalidade como pressuposto. E qualquer política relacionada ao mercado de capitais tem de garantir a todos o conhecimento de informações mínimas sobre os valores mobiliários - mesmo que esse patamar informacional mínimo não seja suficiente para impedir decisões equivocadas.

Essa premissa é bem ilustrada pela distinção entre duas espécies de "tolos" no mercado: os psicológicos e os informacionais. Os primeiros tomam decisões equivocadas por se deixarem levar por suas emoções em detrimento da razão ou porque são atingidos por distorções cognitivas; os segundos agem com base na informação criada intencionalmente para os enganar (AKERLOF; SCHILLER, 2016, p. 11-12).

A exigência de difusão de informações no mercado de capitais visa a promover julgamentos informados dos agentes do mercado, mas não necessariamente acertados. Numa síntese dessa ideia, a lei "não retirou do cidadão 'seu direito inalienável de se fazer de trouxa'. Simplesmente tentou impedir que outros o façam de trouxa" (LOSS; SELIGMAN, 2004, p. 3233). Tais políticas são aptas, portanto, a proteger os tolos informacionais, não os tolos psicológicos.

Uma das principais características de um mercado de capitais eficiente é a sua capacidade funcional alocativa, isto é, a sua habilidade em fazer com que os recursos nele investidos sejam, de modo rápido e dinâmico, direcionados para os projetos de investimento que produzem o melhor retorno econômico (KÜMPEL, 2007, p. 35). Isto faz com que a economia como um todo seja mais eficiente, dado que os projetos mais vantajosos atrairão os escassos recursos existentes, em detrimento dos projetos ineficientes. Para que o mercado possa exercer essa função, é preciso que os preços dos valores mobiliários nele transacionados sejam informativos, ou seja, que se aproximem, na maior medida possível, do seu valor intrínseco².

\footnotetext{
${ }^{2}$ Valor intrínseco é um conceito imaginário, consistente no valor sobre o qual haveria consenso se todos os agentes tivessem todas as informações relevantes a respeito do ativo e todos soubessem exatamente como processar tais informações. Na prática, contudo, ninguém detém todas as informações pertinentes e poucas pessoas sabem processar corretamente tais dados, de modo que o valor intrínseco de um ativo é frequentemente desconhecido. Porém, os mercados podem agregar informações de diferentes fontes para produzir preços que são mais próximos ao valor intrínseco do ativo do que qualquer um poderia conseguir sozinho.
} 
CAVALI, Marcelo Costenaro; IKEDA, Natalia Naomi. Atuações no mercado de capitais combinadas em redes sociais: apontamentos para a atribuição de responsabilidade administrativa e penal por

Para que possam avaliar se um ativo está corretamente "precificado", ou seja, se o seu preço de negociação está próximo do seu valor intrínseco - ou se está subvalorizado ou supervalorizado -, os investidores trabalham com dois tipos de informações.

As informações explícitas compreendem todo tipo de dados diretos de companhias específicas ou do mercado em geral, como relatórios financeiros e notícias econômicas ou mercadológicas. Já as informações implícitas são aquelas que apenas indiretamente expressam dados relevantes, como alterações de preços, volume de negócios, identidade do negociante e fluxo de ordens (GOSHEN; PARCHOMOVSKY, 2006, p. 721).

Vejamos, a seguir, como as condutas manipuladoras afetam as informações das duas espécies, explícitas e implícitas, fornecendo ao mercado sinais falsos a respeito do valor intrínseco dos ativos, tornando o seu preço menos informativo e, por consequência, o mercado e a economia como um todo menos eficientes.

\section{Formas de manipulação do mercado}

Há variadas formas de classificar as espécies de manipulação do mercado. Para os fins deste artigo, importa-nos, apenas, traçar a diferença entre manipulação informacional e manipulação negocial ${ }^{3}$.

A manipulação informacional ocorre por meio da disseminação de falsas informações ou rumores sobre uma companhia, para depreciar ou inflar a cotação de um valor mobiliário e lucrar com esse movimento. Utilizando a estratégia de depreciar o valor do ativo, o manipulador pode, por exemplo, num primeiro momento, vender a ação a descoberto - isto é, alugar a ação e vendê-la, com o compromisso de entregá-la no futuro, de modo que terá de posteriormente adquiri-la no mercado - ou adquirir opções de venda (put options) dessa ação. Em seguida, ele disseminará informações falsas ou distorcidas referentes à companhia, que farão - se sua estratégia for bem-sucedida - com que o preço de negociação da ação caia. Aí, então, ele irá adquirir as ações por esse preço mais baixo - caso as tenha vendido a descoberto -, lucrando a diferença entre o valor pelo qual a vendeu e o valor depreciado artificialmente pela qual a comprou posteriormente, ou - se adquiriu opções de venda - irá vendê-las agora a preços mais valorizados, pois os detentores da ação possuem interesse em vendê-la pelo preço estipulado

\footnotetext{
${ }^{3}$ Numa classificação clássica, ao lado da manipulação baseada em informações (information-based manipulation) e da fundada em transações (trade-based manipulation), haveria, ainda, a manipulação baseada em ações (action-based manipulation) - cf. ALLEN; GALE, 1992. p. 505. Mais recentemente dividiram-se as formas de manipulação descoberta no mercado (naked open market manipulation), manipulação no mercado com um interesse externo (open market manipulation with an external interest) e manipulação por desinformação (misstatement manipulation) - (FOX; GLOSTEN; RAUTERBERG, 2019. p. 203-205).
} 
CA VALI, Marcelo Costenaro; IKEDA, Natalia Naomi. Atuações no mercado de capitais combinadas em redes sociais: apontamentos para a atribuição de responsabilidade administrativa e penal por

nas opções, mais alto do que aquele praticado no mercado após a sua atuação (VILA, 1989, p. 22).

No movimento inverso, é possível forçar para cima o preço das ações de uma companhia por meio da disseminação da informação, por exemplo, de que ela estaria prestes a ser alvo de uma oferta pública de aquisição.

A manipulação informacional atua sobre as informações explícitas disponíveis aos agentes do mercado. É, por isso, normalmente, mais fácil de ser comprovada: se a informação disseminada for sabidamente falsa ou dolosamente distorcida fica evidente a intenção do agente de manipular o preço do valor mobiliário. Eventualmente, porém, a informação distorcida divulgada ao mercado pode ser suficiente para mover os preços dos ativos, mas sem conter uma mentira flagrante - o que dificultará a prova do dolo.

De todo modo, para possuir potencial de gerar lucro ao manipulador, é necessário que a informação distorcida disseminada detenha alguma credibilidade ${ }^{4}$.

Já a manipulação negocial ocorre no próprio mercado, apenas por meio da compra e venda de valores mobiliários, sem que sejam difundidas informações falsas sobre a companhia. Essa forma de manipulação, se realizada isoladamente, possui menor possibilidade de ser bemsucedida, além de ser de mais difícil comprovação.

Nesse caso, a manipulação atinge informações implícitas: os demais agentes vislumbram a alteração de preços, o aumento do volume de negócios, a mudança do fluxo de ordens etc., e identifica uma tendência do mercado que pode influenciá-lo a tomar decisões equivocadas de investimento.

Para que essa forma de manipulação possa gerar lucros ao manipulador, é preciso que: a) a compra das ações gere uma subida de preço do valor mobiliário; e b) a posterior venda seja realizada em circunstâncias nas quais a queda do preço do valor mobiliário seja menos severa; c) de modo que o preço médio de venda exceda o preço médio de compra (FOX; GLOSTEN; RAUTERBERG, 2019, p. 203).

Uma das primeiras formas identificadas de manipulação negocial foi a realizada por grupos pequenos de investidores (pools) que, coordenados, realizam operações concertadas no

\footnotetext{
${ }^{4}$ Especial potencial de manipulação do mercado baseada em informação possuem as informações repassadas ao público por determinadas pessoas - como executivos das companhias, jornalistas especializados no mercado financeiro e alguns analistas de mercado ("gurus") - que ocupam posições que lhes propiciam acesso privilegiado a dados relevantes dos emissores, conferindo-lhes alto grau de credibilidade (BENABOU; LAROQUE, 1992. p. 921-958). Investigações do Congresso americano, antes do advento do Securities Exchange Act, constataram que diversos observadores supostamente isentos, como jornalistas e radialistas, na verdade eram verdadeiros agentes publicitários de empresas especializadas na negociação de valores mobiliários (SELIGMAN; 2003. p. 16-17).
} 
CAVALI, Marcelo Costenaro; IKEDA, Natalia Naomi. Atuações no mercado de capitais combinadas em redes sociais: apontamentos para a atribuição de responsabilidade administrativa e penal por

lado da oferta e da demanda (matched orders). Ocorre a introdução concomitante - ou temporalmente próxima - de ordens de compra e de venda com o mesmo preço e quantidade, por pessoas agindo em conjunto, para que a execução das operações seja exitosa.

Nessa hipótese, embora de difícil comprovação, a manipulação é clara, pois não existe causa real para os negócios jurídicos que são realizados unicamente com o intuito de forçar o preço das ações em determinada direção. Como os manipuladores negociam entre si, os riscos já estão dimensionados e, eventualmente, as perdas e ganhos podem ser repartidos entre os participantes.

Mas esse mesmo grupo de investidores pode fazer uma aposta mais arriscada. Ao invés de realizarem as operações entre si, eles se unem para efetuar suas operações todas no mesmo sentido, "contra" o mercado. Para fazer o preço da ação subir, por exemplo, elevam-se paulatinamente o valor e o volume das ofertas, criando nos demais investidores uma percepção (falsa) de real demanda pelo título. Uma vez atingido o nível esperado, os agentes passam a vender os títulos, lucrando com a diferença das operações (pump-and-dump).

O risco, nesse caso, é maior. E por isso mesmo há quem defenda que não faria sentido proibir esse tipo de manipulação - seria uma conduta autodissuasória -, já que não seria possível auferir lucros por esse meio. Isso porque a manipulação dependeria de duas condições: em primeiro lugar, as negociações teriam de fazer o preço do título subir; depois, o manipulador teria de ser capaz de vender as ações por um preço superior àquele que pagou. A primeira condição seria difícil de atingir em mercados líquidos, pois a cotação das ações dificilmente seria afetada por operações individuais, salvo se realizadas em montantes muito expressivos, que tornariam pouco atrativa a manobra diante do risco envolvido; já a segunda condição seria praticamente impossível de satisfazer, porque a pressão sobre os preços é simétrica, ou seja, os ganhos obtidos na subida do valor da ação seriam perdidos na sua queda (FISCHEL; ROSS, 1991, p. 503-553).

O argumento, embora sedutor, não convence. Embora não seja fácil, é, sim, possível lucrar com a manipulação baseada em negociações (ALLEN; GALE, 1992, p. 514-515). Tudo dependerá da habilidade de o manipulador conseguir adquirir ações em preço razoável antes de forçar o seu preço para cima e de ser bem-sucedido em vendê-las sem afetar da mesma forma o preço para baixo, o que é possível, em tese, por exemplo, pela compra de um grande lote de ações, seguido de diversas vendas em valores menores (THEL, 1994, p. 264-265).

Além disso, o simples fato de existir um risco de autolesão em razão de uma determinada conduta não implica, necessariamente, que ninguém a praticará. Assim, se essa conduta gerar 
CAVALI, Marcelo Costenaro; IKEDA, Natalia Naomi. Atuações no mercado de capitais combinadas em redes sociais: apontamentos para a atribuição de responsabilidade administrativa e penal por manipulação de mercado

dano ou risco de dano a terceiros, ela pode ser reprovável mesmo que haja risco para o próprio agente - basta que se pense no crime de rixa (CP, art. 137).

\section{A manipulação na era das redes sociais}

Há uma crescente descentralização na produção e no consumo de informação. Redes de televisão, emissoras de rádio e jornais são suplantados por mídias alternativas. Propagandas são substituídas por "pessoas "reais", que simplesmente "divulgam" seu cotidiano. Quando os investidores acompanham "influencers", redes de discussão e recebem alertas em tempo real em aplicativos de celular, não parece mais tão relevante ler o noticiário financeiro no dia seguinte (MITTS, 2019, p. 5).

Não podem ser negadas as vantagens produzidas pela evolução das redes sociais e dos meios de comunicação. Tais plataformas foram capazes de impulsionar um impressionante processo de democratização de acesso a informações sobre o mercado financeiro. Por outro lado, porém, também se consolidaram como eficientes ferramentas para potenciais condutas de manipulação de mercado.

Em pesquisa realizada por meio de um algoritmo de inteligência artificial, na qual foram examinadas milhões de publicações na plataforma Twitter e seus efeitos sobre a flutuação dos valores de ações de companhias menores e de baixa liquidez (small caps), um pesquisador da Universidade Sorbonne concluiu haver uma relação direta entre (i) um episódio de aumento anormal do número de postagens na rede social e (ii) uma subsequente elevação dos preços das ações das empresas objeto das mensagens publicadas, (iii) seguida de uma queda brusca de valor ao longo da semana seguinte (RENAULT, 2017).

As redes sociais permitem que informações falsas ou enganosas sejam disseminadas a um grande grupo de investidores com mínimo esforço, de forma anônima - por meio de pseudônimos - e com um custo relativamente baixo. Assim, qualquer pessoa com acesso a uma dessas plataformas tem, em tese, capacidade de afetar diretamente o preço de valores mobiliários - ou de outros instrumentos financeiros - por meio de publicações (posts).

Exemplo disso foi o episódio envolvendo a famosa companhia de distribuição de notícias, GlobeNewswire, e a rede de supermercados Walmart ${ }^{5}$. A GlobeNewswire havia noticiado que o Walmart passaria a aceitar a criptomoeda Litecoin como forma de pagamento em suas unidades - o que causou uma grande movimentação no mercado, levando à súbita

\footnotetext{
${ }^{5}$ https://www.foxbusiness.com/markets/globenewswire-walmart-litecoin-fake-fraudulent-user-account
} 
CAVALI, Marcelo Costenaro; IKEDA, Natalia Naomi. Atuações no mercado de capitais combinadas em redes sociais: apontamentos para a atribuição de responsabilidade administrativa e penal por

valorização da criptomoeda ${ }^{6}$. Horas depois, no entanto, a própria rede de supermercados manifestou-se publicamente negando a notícia, que foi retirada do portal de notícias.

A Litecoin no entanto, já havia alcançado a cotação de $\$ 233,44$, quando a sua média de valor não chegava a $\$ 180$. A GlobeNewswire retratou-se afirmando que a publicação havia sido feita por meio de uma conta de usuário falsa e que estava reforçando seus procedimentos de autenticação.

Outra forma de manipulação via redes sociais é o chamado scalping: sem revelar que detêm investimentos em um determinado valor mobiliário, consultores de investimentos - ou outros inflluencers do mercado - recomendam a seus clientes que também o façam. Quando estes começam a adquirir o papel, o agente introduz ordens de venda dos seus ativos (PINTO, 2000, p. 127). Trata-se, em outras palavras, de "uma espécie de conselho de investimento com segundas intenções" (BANDEIRA, 2011, p. 562).

Conduta dessa espécie foi examinada, por exemplo, em SEC v. Park, em que Yun Soo Oh Park, conhecido como "Tokyo Joe", mantinha um sítio eletrônico para a transmissão de informações sobre ações, cobrando uma mensalidade pelo envio dessas "dicas"7 . Entre outras condutas apontadas pela SEC, o agente adquiria ações de uma companhia e, depois, recomendava a seus seguidores - sem lhes revelar que possuía a ação - que também a adquirissem para, uma vez atingido determinado valor, vendê-las ${ }^{8}$.

Há alguns anos, legisladores e reguladores preocupavam-se tão somente com manipulação de mercado por parte de corporate insiders por serem os únicos atores com acesso a informações relevantes e com posições capazes de influenciar o valor de uma ação. Episódios como o caso GameStop, no entanto, deixam claro que a dinâmica do mercado financeiro foi profundamente alterada pelas novas tecnologias e, em especial, pelo uso de redes sociais, tornando possível que qualquer pessoa - ou grupo de pessoas - tenha o poder de alterar significativamente a cotação de uma ação ${ }^{9}$.

\footnotetext{
${ }^{6}$ Criptomoedas, em princípio, não se enquadram no rol de valores mobiliários previsto no art. $2^{\circ}$ da Lei $\mathrm{n}^{\circ}$ 6.385/1976. De todo modo, estão sujeitos a ataques manipulativos semelhantes àqueles realizados sobre valores mobiliários.

${ }^{7}$ SEC v. Park, F.Supp.2d 889 (N.D.Ill. 2000).

${ }^{8}$ SEC v. Park, F.Supp.2d 889, 901 (N.D.Ill. 2000).

${ }^{9}$ Demonstrada preocupação com essas novas formas de atuação/manipulação, a BSM mencionou, no seu Relatório Anual de 2020, a implantação de ferramentas de supervisão de informações também em blogs, fóruns de discussão na internet e nas redes sociais, para identificar possíveis práticas ilícitas. Cf. BSM Supervisão de Mercados. Relatório Anual de 2020. Disponível em:

https://www.bsmsupervisao.com.br/assets/file/BSM_Relatorio-Anual-2020.pdf. Acesso em 26.09.2021.
} 
CAVALI, Marcelo Costenaro; IKEDA, Natalia Naomi. Atuações no mercado de capitais combinadas em redes sociais: apontamentos para a atribuição de responsabilidade administrativa e penal por manipulação de mercado

\section{Short squeeze sem poder de mercado?}

O sueco Putniņš identifica três formas diferentes de manipular o mercado: forçar tendências de alta ou baixa da cotação (runs), manipular o índice utilizado como parâmetro contratual (contract-based manipulation) e abusar do poder de mercado (market power techniques) (PUTNIN̦Š, 2012, p. 957).

As técnicas enquadradas por Putniņš como abuso de poder de mercado são aquelas, mais comuns nos mercados de mercadorias e futuros, em que o manipulador assegura uma posição de controle sobre a oferta de um ativo ou derivativo e, então, vale-se dessa posição para explorar os investidores que têm necessidade do ativo para fechar suas posições descobertas. Trata-se dos métodos conhecidos como "encurralar" (corner) e "espremer" (squeeze). A diferença entre os métodos não é de natureza, mas de grau: no corner, o manipulador adquire praticamente o monopólio de um determinado ativo, de modo que pode impor seu preço aos vendedores a descoberto, que terão que adquirir o ativo para cobrir suas posições; no squeeze, o manipulador, ciente da elevada demanda e baixa oferta de um determinado ativo no futuro, adquire mais títulos, forçando o preço para cima pela diminuição ainda maior da oferta do ativo e obrigando os vendedores a descoberto a pagarem o preço mais alto estabelecido ${ }^{10}$.

Note-se como o caso GameStop se apresenta como um verdadeiro "ornitorrinco", a colocar em xeque essa classificação. As situações de squeeze não foram perpetradas por agentes detentores de domínio de posição dominante no mercado, com elevado poder econômico, mas por centenas de milhares de investidores, agindo conjuntamente, tornando evidente o poder das transformações causadas pelas redes sociais.

Seja como for, os squeezers tentam restringir de tal modo um lado do mercado que qualquer pessoa que pretenda liquidar a posição do outro lado se vê obrigado a negociar com eles. Se conseguirem, os preços vão às alturas. Eles não atuam baseados em fundamentos econômicos, mas na atuação massiva e no conhecimento das posições do outro lado do

\footnotetext{
${ }^{10} \mathrm{Na}$ definição da Suprema Corte dos EUA, “'running a corner' consiste, genericamente falando, em adquirir controle de toda a oferta de uma commodity ou de uma parte dominante dela, com o propósito de aumentar artificialmente o seu preço, sendo uma das formas mais relevantes de fazê-lo a compra para entrega futura, conectada com uma retenção de venda por um tempo limitado" - United States v. Patten, 226 U.S. 525, 539540 (1913). Já em outro precedente, a Corte de Apelações do Oitavo Circuito definiu que "squeeze é uma situação menos extrema que corner". Neste caso, pode não haver um verdadeiro monopólio da mercadoria à vista, mas por alguma razão a oferta de entrega da mercadoria está reduzida em determinado período, enquanto o interesse sobre a mercadoria no mercado futuro está substancialmente elevado em relação à oferta. $\mathrm{O}$ preço dos futuros pode ser manipulado por um squeeze intencional, em que o manipulador adquire contratos em excesso, detendo parcela substancial destes, forçando os vendedores a descoberto a pagar os preços ditados de forma artificial; a maioria dos vendedores a descoberto não poderá satisfazer os contratos de entrega futura de mercadoria e o preço subirá mais ainda. Cf. Cargill, Incorporated v. Hardin, 452 F.2d 1154, 1162 (8th Cir. 1971).
} 
CAVALI, Marcelo Costenaro; IKEDA, Natalia Naomi. Atuações no mercado de capitais combinadas em redes sociais: apontamentos para a atribuição de responsabilidade administrativa e penal por manipulação de mercado

mercado. Por tentarem lucrar somente ferindo outros investidores, são chamados de “investidores-parasitas" (HARRIS, 2003, p. 245).

\section{A infração administrativa de manipulação de preços (Instrução CVM nº 08/1979)}

A manipulação de preços está definida na Instrução CVM no 08/1979 como "a utilização de qualquer processo ou artifício destinado, direta ou indiretamente, a elevar, manter ou baixar a cotação de um valor mobiliário, induzindo terceiros à sua compra ou venda" (art. II. "a”). Na visão da CVM, os elementos da infração podem ser decompostos da seguinte forma: i) utilização de processo ou artifício; ii) destinado a promover cotações enganosas ou artificiais; iii) induzindo terceiros a negociar valores mobiliários cujas cotações foram artificialmente produzidas; iv) presença do dolo, ainda que eventual, de alterar as cotações e induzir terceiros a negociar com base nessas cotações falsas ${ }^{11}$.

Num caso emblemático relacionado a uma companhia produtora de alicates - que ficou conhecido como "a bolha do alicate" -, o Colegiado da autarquia condenou um agente autônomo de investimentos que negociou, durante um período estendido, lotes mínimos de ações, em inúmeros negócios, sempre buscando elevar a cotação do ativo, além de estimular seus clientes, sócios e demais participantes do mercado a promover "o milagre da multiplicação dos preços das ações"12.

A atuação coordenada de investidores para forçar o preço de uma ação pode, em tese, caracterizar a manipulação de preços. A reunião, ainda que virtual, de pessoas que decidem adquirir papéis com o objetivo único e deliberado de fazer a sua cotação subir caracteriza um artifício destinado a promover cotações enganosas ou artificiais.

Com efeito, não se trata de decisões tomadas a partir de uma análise sobre o valor fundamental do papel ou de uma previsão sobre quanto ele virá a valer. Trata-se de uma profecia autorrealizável, porque a cotação apenas sobe em razão da atuação dos envolvidos. Não há uma formação de preços baseada na oferta e na demanda reais, mas num movimento artificialmente criado pelas "sardinhas".

O objetivo dessa operação pode ser tanto o de causar prejuízo aos investidores que operam vendidos como induzir terceiros a negociar os valores mobiliários cujas cotações foram artificialmente produzidas. Evidentemente, trata-se de conduta dolosa.

\footnotetext{
${ }^{11}$ CVM, PAS no RJ2013/5194, j. 19.12.2014, Rel. Ana Dolores Moura Carneiro de Novaes.
}

${ }^{12}$ CVM, PAS no RJ2012/11002, j. 08.12.2016, Rel. Dir. Roberto Tadeu Antunes Fernandes. 
CAVALI, Marcelo Costenaro; IKEDA, Natalia Naomi. Atuações no mercado de capitais combinadas em redes sociais: apontamentos para a atribuição de responsabilidade administrativa e penal por manipulação de mercado

Embora em um caso de movimento articulado de milhares de investidores exista evidente dificuldade probatória para se identificar os responsáveis pelo artifício, a reconstrução das mensagens enviadas em redes sociais pode caracterizar um indício a ser aprofundado pelas autoridades.

No caso da GameStop, há, ao menos, indícios razoáveis de quem seria o principal articulador do esquema. Segundo consta de uma ação movida por uma autodeclarada vítima do esquema, depois de comprar um número considerável de ações da GameStop, por aproximadamente \$5, Keith Gill - um investidor com mais de quinze anos de experiência no mercado de capitais, tendo trabalhado em várias instituições financeiras - teria utilizado várias identidades para promover as ações da companhia nas mídias sociais. Ele utilizou os pseudônimos "Roaring Kitty" no YouTube - onde gatos são um dos temas mais buscados - e no Twitter, assim como "DeepFuckingValue" no quadro de mensagens WallStreetBets (com nove milhões de participantes) da rede social Reddit. Nesses locais, ele se apresentava como um amador, uma espécie de "Robin Hood", defensor dos pequenos investidores. Ele manifestou expressamente a intenção de colocar os fundos que operava vendidos em short squeeze, orientando os demais investidores a comprarem e segurarem a ação, com o propósito declarado de gerar dano a quem se encontrasse na posição vendida. O valor da ação subiu mais de $1.600 \%$, até $\$ 483$.

Não apenas sofreram prejuízos fundos de investimento - que, vale lembrar, não congregam necessariamente recursos de pessoas ricas, mas também de pequenos investidores -, mas também outros agentes que, analisando o mercado, concluíram pela falência do modelo de negócios da GameStop.

Outros fatores devem ser levados em consideração para a apuração da real intenção do suposto manipulador. Por exemplo, pode-se verificar as posições que foram montadas antes da incitação a operar e buscar associar estas operações às pessoas que escreveram as mensagens (COSTA, 2021, p. 132). Deve-se examinar o conteúdo das postagens feitas por ele e comparálas com as operações concomitantemente realizadas. Deve-se verificar o seu histórico de operações e de manifestações em redes sociais, com o papel negociado e outros. Deve-se verificar a veracidade das informações postadas. Deve-se comparar o valor aplicado com a carteira total do investigado. Deve-se verificar se ele manteve os papéis no longo prazo; depois do vencimento dos contratos de quem estava operando vendido, haverá um argumento favorável à existência de razões justificáveis para a aquisição das ações. 
CAVALI, Marcelo Costenaro; IKEDA, Natalia Naomi. Atuações no mercado de capitais combinadas em redes sociais: apontamentos para a atribuição de responsabilidade administrativa e penal por manipulação de mercado

Seja como for, os casos recentes demonstram que não apenas "tubarões" conseguem manipular o mercado - cardumes de "sardinhas", comandados por um ou mais peixes, podem produzir o mesmo efeito.

\section{Aspectos criminais da manipulação de mercado}

Além da punição administrativa, a manipulação de mercado é tipificada como crime no art. 27-C da Lei $n^{\circ}$ 6.385/1976. O tipo penal não remete expressamente a nenhuma regulamentação administrativa. Nem por isso, no entanto, a regulamentação administrativa assim como a jurisprudência administrativa, especialmente da CVM - deixa de exercer um papel relevante no desenho da moldura típica, pois sua análise é fundamental para a compreensão de elementos normativos e para a delimitação do risco proibido ao bem jurídico.

A caracterização do ilícito administrativo da manipulação de mercado, em ao menos uma das formas previstas na Instrução CVM n 0 08/1979, é condição necessária - conquanto insuficiente - para a perfectibilização do delito de manipulação de mercado (Lei n ${ }^{\circ}$ 6.385/1976, art. 27-C). Apesar de o tipo penal não fazer referência expressa à regulamentação administrativa, a estrutura linguística de ambos - especialmente em relação às figuras da criação de condições artificiais de demanda, oferta ou preço e da manipulação de preço de valores mobiliários - é de tal maneira intrincada que não se visualiza a possibilidade de que o delito se caracterize sem a violação concomitante das normas administrativas.

As regras administrativas que disciplinam o mercado de capitais desenham o risco permitido nessa seara. Se, em sua atuação no mercado, o agente obedecer às regras de negociação estabelecidas pelo autorregulador e pelo regulador, não terá criado risco proibido ao bem jurídico protegido pela norma penal.

Assim, se, por um lado, nem todas as condutas que caracterizem a infração administrativa de manipulação do mercado poderão subsumir-se à hipótese de incidência do tipo penal, qualquer conduta penalmente típica terá de preencher, igualmente, os elementos de alguma das figuras ilícitas administrativas.

\subsection{Toda infração administrativa de manipulação de mercado também é criminosa?}

Não é pacífica, porém, a determinação de quais são as infrações administrativas que foram incorporadas ao tipo penal (CAVALI, 2018, p. 241-265). Para alguns estudiosos, comentando ainda o tipo penal na redação da Lei n ${ }^{\circ} 10.303 / 2001$, o legislador teria reunido no 
CAVALI, Marcelo Costenaro; IKEDA, Natalia Naomi. Atuações no mercado de capitais combinadas em redes sociais: apontamentos para a atribuição de responsabilidade administrativa e penal por manipulação de mercado

tipo penal elementos de, ao menos, três dos ilícitos administrativos: criação de condições artificiais de demanda, oferta ou preço de valores mobiliários; manipulação de preços; e realização de operação fraudulenta (EIZIRIK; GAAL; PARENTE; HENRIQUES, 2011, p. 539). Com isso, teria sido deixada de fora a punição das condutas enquadradas administrativamente como práticas não equitativas (GONÇALVES, 2011, p. 14).

Para outros autores, o tipo penal teria abrangido todas as infrações administrativas, inclusive as práticas não equitativas (BITENCOURT; BREDA, 2010, p. 339-340). Havia ainda quem entendesse que somente a manipulação de preços e a operação fraudulenta estariam abrangidas pelo tipo penal, que não contemplaria, portanto, nem as práticas não equitativas nem a criação de condições artificiais de demanda, oferta ou preço de valores mobiliários (PUGLIESE; NAJAR, 2015, p. 263).

Tanto na redação original, como naquela veiculada pela Lei n ${ }^{\circ} 13.506 / 2017$, é a partir do bem jurídico protegido que a questão deve ser examinada. Entendemos que o bem jurídico protegido é capacidade funcional alocativa do mercado, especificamente o mecanismo de regular formação de preços dos valores mobiliários. Essa premissa reflete de modo determinante na interpretação do tipo penal e nas suas relações com as infrações administrativas (CAVALI, 2018, p. 340-348).

A prática não equitativa pressupõe uma posição de desigualdade entre o agente que comete a infração e o prejudicado, bem como a violação de um dever fiduciário por parte daquele em detrimento deste. Tais pressupostos, suficientes para a caracterização da infração administrativa, podem ser preenchidos sem que ocorra nenhuma operação simulada ou manobra fraudulenta - sendo uma delas, ao menos, imprescindível para a realização do delito.

Por exemplo, apesar de o tipo penal se referir a "manobras fraudulentas", a maioria das condutas, que na jurisprudência da CVM são consideradas como operações fraudulentas, (Instrução CVM nº 08/1979, item II, alínea “c”) não caracterizará o delito de manipulação do mercado (Lei n 6.385/1976, art. 27-C).

Boa parte desses casos consiste em venda de ações sem autorização do seu titular ou com base em autorização falsa. Se exigida a potencial interferência indevida no processo de formação de preços - de acordo com a interpretação voltada à proteção do bem jurídico assumida neste artigo -, tais condutas, no mais das vezes, não configurarão o delito do art. 27 $\mathrm{C}$ da Lei $\mathrm{n}^{\circ}$ 6.385/1976, dado que se trata, em regra, da venda de ações líquidas, em quantidades 
CAVALI, Marcelo Costenaro; IKEDA, Natalia Naomi. Atuações no mercado de capitais combinadas em redes sociais: apontamentos para a atribuição de responsabilidade administrativa e penal por

reduzidas, pelo preço de mercado. Não possuem tais operações sequer potencial de afetação do bem jurídico ${ }^{13}$.

Em conclusão, a violação da disciplina regulamentar do mercado de capitais é pressuposto para o cometimento do delito de manipulação de mercado, mas a prática da infração administrativa não implica necessariamente preenchimento dos elementos do tipo penal.

\subsection{A imputação do crime de manipulação em atuação combinada em redes sociais}

Se a atuação combinada em redes sociais pode caracterizar a infração administrativa de manipulação de preços, também é possível que se esteja diante de um crime de manipulação de mercado.

A maior dificuldade para o enquadramento consiste em identificar se há ou não manobra fraudulenta na atuação de quem orienta centenas/milhares de outras pessoas a comprar/vender/manter ações, já que não há dúvida de que as operações são destinadas a elevar a cotação do valor mobiliário, nem sobre o fim de obter lucro e de causar dano a terceiros.

Compreende-se como fraudulenta toda manobra maliciosa que leve terceiros a uma falsa percepção da realidade. Ainda que as redes sociais sejam acessíveis a qualquer pessoa, a maioria do mercado continua a ser mantida em erro quanto à razão pela qual os ativos estão sendo comprados. Sem tomar conhecimento do acerto na rede social, os demais investidores acreditarão falsamente haver razões econômicas reais a direcionar o movimento das cotações. É perfeitamente possível falar-se em fraude, portanto.

Se alguém assume a frente desse processo, criando perfis anônimos e dirigindo outros investidores, de modo sistemático e programado, para a compra ou venda de um determinado ativo, ostensivamente sem fundamento econômico algum - com o objetivo declarado de forçar o preço de negociação em determinado sentido -, essa conduta será considerada manipuladora.

Mais uma vez vale fazer referência ao caso da "bolha do alicate", anteriormente examinado no que se refere à esfera administrativa, em que um agente autônomo de investimentos negociou lotes mínimos de ações, inúmeras vezes, com o objetivo de elevar a cotação do ativo, além de estimular seus clientes, sócios e demais participantes do mercado a fazerem o mesmo. Esse caso também foi objeto de ação penal, tendo o Tribunal Regional Federal da $4^{\mathrm{a}}$ Região concluído pela ocorrência do crime de manipulação de mercado, ao ressaltar que o réu utilizou diferentes estratégias para aumentar o volume de negócios

${ }^{13}$ A conduta, neste caso, pode caracterizar o delito do art. $5^{\circ}$ da Lei $n^{\circ} 7.492 / 1986$, estelionato (CP, art. 171) ou apropriação indébita comum (CP, art. 168). 
CAVALI, Marcelo Costenaro; IKEDA, Natalia Naomi. Atuações no mercado de capitais combinadas em redes sociais: apontamentos para a atribuição de responsabilidade administrativa e penal por manipulação de mercado

envolvendo as ações da Mundial S.A., como o uso de robôs de alta frequência, a persuasão de clientes para comprar e manter os títulos e a divulgação de notícias positivas na mídia especializada acerca da situação da companhia. Especificamente acerca do argumento de que a compra de ações em lotes mínimos, pelo réu, constitui conduta socialmente aceita no mercado imobiliário, o TRF4 assentou que isso seria irrelevante, dado o "elemento volitivo específico de impulsionar a manipulação do mercado", demonstrado pelo contexto das comunicações com os clientes do réu ${ }^{14}$.

É claro que, em casos semelhantes ao da GameStop, o Ministério Público não terá condições de processar todos os envolvidos na fraude. E, mesmo que isso fosse possível, em relação à maioria das pessoas que forçaram o preço para cima haverá apenas provas de que participaram das negociações - mas não de que tomaram a frente da direção da manobra fraudulenta.

Mais do que a efetiva responsabilização de todos os participantes, o mais importante é deixar claro que, em tese, essa atribuição de responsabilidade, inclusive criminal, é possível. E, em casos mais graves, será fundamental levar a cabo uma investigação rigorosa e aprofundada, para punição, ao menos, do(s) principal(is) artífices(s) do esquema, a fim de gerar um efeito de prevenção geral contra esse tipo de conduta.

\section{Referências}

AKERLOF, George; SCHILLER, Robert. À pesca de tolos: a economia da manipulação e do logro. Trad. Pedro Elói Duarte. Coimbra: Conjuntura Actual. 2016.

ALLEN, Franklin; GALE, Douglas. Stock-price manipulation. The review of financial studies. Oxford: Oxford University Press, v. 5, i. 3, 1992.

BANDEIRA, Gonçalo S. de Melo. Abuso de mercado e responsabilidade penal das pessoas (não) colectivas: contributo para a compreensão dos bens jurídicos colectivos e dos “tipos cumulativos” na mundialização. Curitiba: Juruá, 2011.

BENABOU, R.; LAROQUE, G. Using privileged information to manipulate markets: insiders, gurus and credibility. Quarterly journal of economics. Cambridge: Oxford University Press, v. 107, n. 3, Aug. 1992.

BITENCOURT, Cezar Roberto; BREDA, Juliano. Crimes contra o sistema financeiro nacional e contra o mercado de capitais. Rio de Janeiro: Lumen Juris, 2010.

${ }^{14}$ TRF4, Apelação Criminal 5015871-75.2020.4.04.7100, Sétima turma, Rel. Juiz. Fed. convocado Danilo Pereira Junior, j. 20.10.2020. 
CA VALI, Marcelo Costenaro; IKEDA, Natalia Naomi. Atuações no mercado de capitais combinadas em redes sociais: apontamentos para a atribuição de responsabilidade administrativa e penal por

BRASIL. Tribunal Regional Federal da $4^{a}$ Região. Apelação Criminal 5015871-

75.2020.4.04.7100, Sétima Turma, Rel. Juiz Fed. convocado Danilo Pereira Junior, j. 01.06.2021.

BRASIL. Comissão de Valores Mobiliários. PAS n⿳0 RJ2012/11002. Rel. Dir. Roberto Tadeu Antunes Fernandes, j. 08.12.2016.

BRASIL. Comissão de Valores Mobiliários. PAS nº RJ2013/5194. jRel. Ana Dolores Moura Carneiro de Novaes, j. 19.12.2014.

CAVALI, Marcelo Costenaro. Manipulação do mercado de capitais: fundamentos e limites da repressão penal e administrativa. São Paulo: Quartier Latin, 2018.

CAVALI, Marcelo Costenaro; BALDINI, Alessandra Gomes Faria. Insider trading: fundamentos econômicos e éticos da proibição do uso indevido de informação privilegiada. In: SANTIAGO, Marcus Firmino; SAYEG, Ricardo Hasson (coord). Transformações na ordem social e econômica e regulaçãoFlorianópolis: CONPEDI, 2021.

COSTA, Isac Silveira da. "Game over" ou "new game": o caso Gamestop e a metamorfose da manipulação de preços. Revista de Direito das Sociedades e Valores Mobiliários, São Paulo: Almedina, n. 13, maio 2021.

EIZIRIK, Nelson; GAAL, Ariádna B.; PARENTE, Flávia; HENRIQUES, Marcus de Freitas. Mercado de capitais: regime jurídico. Rio de Janeiro; São Paulo; Recife: Renovar, 2011.

FISCHEL, Daniel; ROSS, David. Should the law prohibit "manipulation" in financial markets? Harvard law review. Cambridge: The Harvard Law Review Association, v. 105, n. 2, Dec. 1991.

FOX, Merrit B.; GLOSTEN, Lawrence R.; RAUTERBERG, Gabriel V. The new stock market: law, economics, and policy. New York: Columbia University Press, 2019.

GONÇALVES, Alexandre Manoel. O crime de manipulação no mercado de capitais. Revista Criminal, São Paulo: Fiuza, n. 5, v. 13, jan./abr. 2011.

GOSHEN, Zohar; PARCHOMOVSKY, Gideon. The essential role of securities regulation. Duke law journal. Durham: Duke University Press, v. 55, n. 4, Feb. 2006.

HARRIS, Larry. Trading and Exchanges: market microstructure for practitioners. New York: Oxford University Press, 2003.

KÜMPEL, Siegfried. Direito do mercado de capitais: do ponto de vista do direito europeu, alemão e brasileiro. Rio de Janeiro; São Paulo; Recife: Renovar, 2007.

LOSS, Louis; SELIGMAN, Joel. Fundamentals of securities regulation. 5. ed. New York: Aspen Publishers, 2004.

MICHAELS, Dave; OSIPOVICH, Alexander. The Wall Street Journal. New York, 28 jan. 2021. Disponível em: https://www.wsj.com/articles/gamestop-surge-tests-scope-of-secsmanipulation-rules-11611838175. Acesso em: 26 nov. 2021. 
CA VALI, Marcelo Costenaro; IKEDA, Natalia Naomi. Atuações no mercado de capitais combinadas em redes sociais: apontamentos para a atribuição de responsabilidade administrativa e penal por manipulação de mercado

MITTS, Joshua. A legal perspective on technology and the capital markets: social media, short activism and the algorithmic revolution (out. 28, 2019). Columbia Law and Economics Working Paper n. 615, Disponível em: SSRN: https://ssrn.com/abstract=3447235 ou http://dx.doi.org/10.2139/ssrn.3447235. Acesso em: 26.11.2021.

OSIPOVICH, Alexander. GameStop Stock Frenzy: What You Need to Know. The Wall Street Journal. New York, 27 jan. 2021. Disponível em: https://www.wsj.com/articles/howgamestops-reddit-and-options-fueled-stock-rally-happened-11611743400?mod=article_inline. Acesso em: 26 nov. 2021.

PINTO, Frederico de Lacerda da Costa. O novo regime dos crimes e contra-ordenações no Código dos Valores Mobiliários. Coimbra: Almedina, 2000.

PUGLIESE, Yuri Sahione; NAJJAR, Gabriella. O processo administrativo sancionador da CVM e o crime de manipulação de mercado. Revista de direito das sociedades e dos valores mobiliários, São Paulo: Almedina, v. 1, maio 2015.

PUTNIN̦Š, Tãlis J. Market manipulation: a survey. Journal of economic surveys. Oxford: Blackwell, v. 26, i. 5, Dec. 2012.

RENAULT, Thomas. Market Manipulation and suspicious stock recommendations on social media, Dec. 20, 2017. DOI: http://dx.doi.org/10.2139/ssrn.3010850. Disponível em: https://ssrn.com/abstract=3010850. Acesso em: 16 dez. 2021.

SELIGMAN, Joel. The transformation of Wall Street: a history of the Securities and Exchange Commission and modern corporate finance. Aspen: New York, 2003.

THALER, Richard. Misbehaving: the making of behavioral economics. New York: Norton, 2015.

THEL, Steve. $\$ 850.000$ in Six Minutes - The Mechanics of Securities Manipulation. Cornell Law Review. Ithaca: Cornell University, v. 79, i. 2, Jan. 1994.

VALENTI, Graziella. O IRB e o dilema da CVM: multidão manipula mercado ou é o mercado? Revista Exame. São Paulo, 28 jan. 2021. Disponível em:

https://exame.com/exame-in/o-irb-e-o-dilema-da-cvm-multidao-manipula-mercado-ou-e-omercado/. Acesso em: 26 nov. 2021.

VILA, Jean-Luc. Simple games of market manipulation. Economics letters. North-Holland: Elsevier, v. 29, 1989. 